\title{
Tea or coffee? A case study on evidence for dietary advice
}

\author{
Colin W Binns*, Andy H Lee and Michelle L Fraser \\ School of Public Health, Curtin University of Technology, GPO Box U 1987, Perth, WA 6845, Australia
}

Submitted 20 May 2007: Accepted 6 October 2007: First published online 16 January 2008

\begin{abstract}
The present paper explores the level of evidence required to justify giving dietary advice to the public. There are important practical differences between the development of public health nutrition guidelines and guidelines for clinical practice. While the gold standard for evidence for clinical practice guidelines is a meta-analysis of a number of randomised controlled trials, this is often unrealistic and sometimes unethical for the evaluation of public health nutrition interventions. Hence, epidemiological studies make up the bulk of evidence for nutrition guidelines. Tea and coffee are an interesting case study in relation to this issue. They are two of the most commonly consumed beverages worldwide, yet there is little dietary advice on their use. The evidence for a relationship between coffee or tea consumption and several diseases is discussed. The available studies, predominantly epidemiological, together with animal and in vitro studies, indicate that coffee and tea are both safe beverages. However, tea is the healthier option because it has a possible role in the prevention of several cancers and CVD. While the evidence for such relationships is not strong, the public will continue to drink both tea and coffee, and will continue to ask nutritionists to make recommendations. It is therefore argued that advice should be given on the best available data, as waiting for complete data to become available could have severe consequences for public health.
\end{abstract}

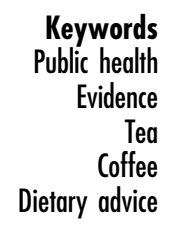

Everyone eats and drinks a variety of foods and beverages each day. The reasons for food choice are multiple, including culture, individual preference, cost, availability and the influence of advertising, as well as dietary advice from a variety of experts ${ }^{(1)}$. Every day the public receives dietary advice from many sources, both reliable and unreliable, making it difficult to decide what is appropriate advice. Complete data on the intake of a particular food or dietary pattern in relation to health benefits or risks can take decades to emerge. Even then the data may not reach the level of evidence usually required for therapeutic interventions. Just how much evidence is sufficient to make public health guidelines? Tea and coffee present an interesting case study in regard to this issue.

Although tea and coffee are two of the beverages most commonly consumed, little dietary advice on their consumption exists ${ }^{(2)}$. Evidence has suggested that tea may play a role in the prevention of several cancers and CVD. As these are two of the largest causes of morbidity and mortality in the world ${ }^{(3)}$, waiting for complete data to become available before providing information to the public could result in unnecessary morbidity and mortality. The present paper examines the existing evidence, predominantly from epidemiological studies, on the relationship between coffee, tea and several chronic health conditions. It also considers whether evidence is currently sufficient to make any level of dietary recommendations.

\section{Making dietary guidelines: how much evidence is required?}

The objective of public health nutrition is to optimise longevity and health for the individual and diet is an extremely important determinant of health ${ }^{(4)}$. Chronic diseases, by definition, have a long natural history, taking decades to develop and are likely to be multi-factorial in causation $^{(4)}$. This complicates nutritional epidemiology, and different approaches have been advocated for obtaining evidence on nutrition. The epidemiological or bottom-up approach, followed by most mainstream nutritional epidemiologists, involves studying particular diseases and then finding common elements within diets that increase or decrease their risk ${ }^{(5)}$. The ecological or top-down approach instead uses the experience of different cultures whose diets appear to protect against morbidity and mortality ${ }^{(5)}$. This latter approach has been advocated by experts ${ }^{(6)}$ to illustrate the apparent 
advantages of the Mediterranean and Japanese diets with regard to $\mathrm{CHD}^{(7)}$. Both approaches have strengths and weaknesses, so combining evidence may have considerable advantages.

Evidence on the optimal diet for longevity and health is most often communicated to the public through dietary guidelines $^{(4)}$. The process of development of these guidelines is sophisticated, with an increasing amount of scientific evidence required to justify decisions ${ }^{(4)}$. Several classifications of the hierarchies of evidence have been developed; for example, by the Australian National Health and Medical Research Council (NHMRC) ${ }^{(8)}$ (see Table 1). The gold standard for all systems is a metaanalysis or pooled analysis of data from a number of randomised controlled trials $(\mathrm{RCT})^{(9)}$. However, epidemiological studies make up the bulk of evidence for nutritional guidelines and these are usually classified as Level III evidence, including cohort, case-control and comparative ecological studies with historical controls ${ }^{(8)}$. Although these study designs have some inherent errors, they can provide helpful evidence of a likely role of diet in affecting health ${ }^{(10)}$.

The NHMRC states: 'A decision should be made about what is feasible and appropriate in a given situation and the extent to which reasonable standards have been met by the available body of evidence, ${ }^{(8)}$. There are important practical differences between the development of public health nutrition guidelines and guidelines for clinical practice $^{(4)}$. Since everyone eats every day, the option of no treatment (or no advice) is not available. Consideration must then be given to the level of evidence required to justify action in the context of dietary advice ${ }^{(11)}$. Achieving the NHMRC's highest standard is typically unrealistic and inappropriate in the field of nutrition ${ }^{(9)}$. RCT frequently cannot be applied to evaluate public health interventions; it would either be unethical or impractical to randomise or use controls due to difficulty in blinding or the length of time required ${ }^{(4,9,10)}$. Cost is usually

Table 1 National Health and Medical Research Council levels of evidence for clinical practice guidelines ${ }^{(8)}$

I Evidence obtained from a systematic review of all relevant randomised controlled trials

II Evidence obtained from at least one properly designed randomised controlled trial

III-1 Evidence obtained from well-designed pseudo randomised controlled trials (alternate allocation or some other method)

III-2 Evidence obtained from comparative studies (including systematic reviews of such studies) with concurrent controls and allocation not randomised, cohort studies, case-control studies, or interrupted time series with a control group

III-3 Evidence obtained from comparative studies with historical control, two or more single-arm studies, or interrupted time series without a parallel control group

IV Evidence obtained from case series, either post-test or pre-test/post-test substantial, and sometimes prohibitive, in public health $\mathrm{RCT}^{(11)}$. Consequently, observational studies or shortterm interventions using biomarkers or interim end points, together with ecological studies, must be utilised ${ }^{(4)}$. This situation is not perfect, yet waiting for complete data to become available could deprive the public of health benefits. Nutritionists are obliged to make dietary recommendations based on the best evidence available.

\section{Case study: tea and coffee}

There has been considerable interest in researching the health effects of tea and coffee. The majority of evidence comes from epidemiological studies, backed up by animal studies, in vitro studies and some short-term human interventions using biomarkers or other interim end points. The PubMed database was searched for systematic and other reviews of epidemiological studies, using the keywords 'tea' + selected disease, such as 'colorectal cancer' and 'cardiovascular disease', and similarly for 'coffee' + selected disease. Studies published in English since the year 2000 were included and full text copies of the papers were obtained. A total of 58 published reviews were obtained. Studies in the reviews were then tabulated, after which PubMed was searched again for additional epidemiological studies. Tables 2 and 3 summarise studies for coffee and tea, respectively. A full list of references can be provided upon request. A method employed by the World Cancer Research Fund ${ }^{(12)}$ to rate the level of current evidence for foods and cancer prevention was adopted. The objective was to assess whether the evidence is convincing, probable, possible or insufficient that coffee or tea decreases risk, has no relationship to, or increases risk of a particular disease. Tables 4 and 5 list the level of evidence for coffee and tea, respectively, and particular diseases.

\section{Coffee: effects on bealth}

\section{Cancers}

Coffee has been suspected of increasing the risk of several cancers but this has not been confirmed by further research. Two reviews on coffee consumption and breast cancer reported that studies consistently showed no relationship ${ }^{(12,13)}$. From the thirty-four studies identified, evidence that the consumption of coffee has no relationship with breast cancer risk is convincing.

While an early pooled analysis of eight studies on pancreatic cancer reported an OR of $1 \cdot 4$ (95\% CI $1 \cdot 1$, $1 \cdot 8)$ for high $v$. low consumption ${ }^{(14)}$, subsequent reviews ${ }^{(12,13,15,16)}$ and a total of forty-five studies located indicated coffee could not be identified as a risk factor. The majority of evidence from two reviews of coffee and ovarian cancer ${ }^{(13,17)}$ and a total of seventeen studies also reported no association. In addition, two reviews ${ }^{(12,18)}$ 
Table 2 Number of reviews and epidemiological studies on coffee and selected diseases

\begin{tabular}{|c|c|c|c|c|c|}
\hline Disease & $\begin{array}{c}\text { Reviews } \\
\text { (epidemiological } \\
\text { studies) }\end{array}$ & Cohort & Case-control & Cross-sectional & $\begin{array}{c}\text { Total } \\
\text { epidemiological } \\
\text { studies }\end{array}$ \\
\hline \multicolumn{6}{|l|}{ Cancers } \\
\hline Breast cancer & 2 & 9 & 25 & 0 & 34 \\
\hline Pancreatic cancer & 5 & 14 & 31 & 0 & 45 \\
\hline Ovarian cancer & 2 & 2 & 15 & 0 & 17 \\
\hline Renal cancer & 2 & 3 & 13 & 0 & 16 \\
\hline Thyroid & 1 & 0 & 12 & 0 & 12 \\
\hline Prostate & 2 & 8 & 8 & 0 & 16 \\
\hline Urinary tract cancer & 7 & 10 & 78 & 0 & 88 \\
\hline Colorectal & 4 & 14 & 35 & 0 & 49 \\
\hline CVD & & & & & $>100^{*}$ \\
\hline \multicolumn{6}{|l|}{ Other conditions } \\
\hline Type 2 diabetes & 5 & 16 & 0 & 11 & 27 \\
\hline Parkinson's disease & 2 & 8 & 12 & 0 & 20 \\
\hline Liver cirrhosis & 0 & 4 & 3 & 0 & 7 \\
\hline $\begin{array}{l}\text { Reproductive } \\
\text { adversities }\end{array}$ & 24 & & & & $>100^{*}$ \\
\hline Bone health & 1 & 13 & 5 & 22 & 40 \\
\hline Gallstones & 0 & 3 & 7 & 2 & 12 \\
\hline Rheumatoid arthritis & 0 & 4 & 2 & 1 & 7 \\
\hline
\end{tabular}

${ }^{*}$ For conditions with over 100 epidemiological studies, the number of studies was not counted.

Table 3 Number of reviews and epidemiological studies on tea and selected diseases

\begin{tabular}{|c|c|c|c|c|c|}
\hline Disease (tea type) & $\begin{array}{c}\text { Reviews } \\
\text { (epidemiological } \\
\text { studies) }\end{array}$ & Cohort & Case-control & Cross-sectional & $\begin{array}{l}\text { Total } \\
\text { epidemiological } \\
\text { studies }\end{array}$ \\
\hline \multicolumn{6}{|l|}{ Cancers } \\
\hline Gastric (green) & 3 & 6 & 19 & 2 & 27 \\
\hline Gastric (black) & 1 & 3 & 16 & 0 & 19 \\
\hline Colorectal (green) & 5 & 3 & 6 & 0 & 9 \\
\hline Colorectal (black) & 3 & 6 & 15 & 0 & 21 \\
\hline Breast (green) & 3 & 4 & 5 & 0 & 9 \\
\hline Breast (black) & 2 & 7 & 10 & 0 & 17 \\
\hline Ovarian & 1 & 3 & 8 & 0 & 11 \\
\hline Prostate & 6 & 5 & 6 & 0 & 11 \\
\hline Lung & 2 & 5 & 10 & 0 & 15 \\
\hline Urinary tract/bladder & 4 & 31 & 8 & 0 & 39 \\
\hline Thyroid & 1 & 0 & 10 & 0 & 10 \\
\hline Oesophagus & 2 & 21 & 3 & 0 & 24 \\
\hline \multicolumn{6}{|l|}{ CVD } \\
\hline $\mathrm{CHD}$ & & 9 & 2 & 1 & 12 \\
\hline Myocardial infarction & & 3 & 8 & 0 & 11 \\
\hline Stroke & & 5 & 1 & 1 & 7 \\
\hline
\end{tabular}

and a total of sixteen studies located on renal cancer, a pooled analysis of nine case-control studies on thyroid cancer $^{(19)}$, and two reviews ${ }^{(12,20)}$ and a total of sixteen studies on prostate cancer, all showed no substantial associations. On the basis of currently available evidence, coffee consumption probably has no relationship with the risk of pancreatic, ovarian, renal, thyroid or prostate cancer.

However, seven reviews located on urinary tract or bladder cancer reported possible slight increased risks with coffee consumption ${ }^{(12,13,21-25)}$. While two systematic reviews calculated increased risks of approximately $20 \%{ }^{(23)}$ and $26 \%{ }^{(25)}$, a European-based review found an increased risk only for drinkers of 10 cups or more per $\mathrm{d}^{(22)}$. Despite the large number (eighty-eight) of studies located, evidence only suggested a possible slightly increased risk at high levels of consumption. Moreover, the majority of animal studies have shown no carcinogenic effects for coffee ${ }^{(26)}$. Moderate consumption of coffee probably has no relationship with the risk of urinary tract or bladder cancer.

On the other hand, four reviews of coffee and colorectal cancer suggested a possible protective effect $^{(12,13,27,28)}$. A meta-analysis of twelve case-control studies reported a pooled relative risk (RR) of $0.72(95 \%$ CI $0 \cdot 61,0 \cdot 84$ ) for high $v$. low coffee consumption ${ }^{(27)}$. 
Table 4 Amount of evidence for coffee and selected conditions

\begin{tabular}{lll}
\hline Evidence & Decreases risk & \multicolumn{1}{c}{ No relationship } \\
\hline Convincing & & Breast cancer \\
Probable & & Pancreatic cancer \\
& & Ovarian cancer \\
& Renal cancer \\
& & Thyroid cancer \\
& Prostate cancer \\
& Urinary tract/bladder cancer \\
& CVD \\
& & Reproductive adversities \\
& & Bone health \\
Possible & & Gallstones \\
& & Rheumatoid arthritis \\
& Colorectal cancer & \\
Insufficient & Type 2 diabetes & \\
\hline
\end{tabular}

Table 5 Amount of evidence for tea and selected conditions



Among a total of forty-nine studies identified, the majority of case-control studies suggested an inverse association but the pattern of risk in cohort studies was unclear. Another review of five cohort studies did not support a protective effect ${ }^{(29)}$. Several plausible biological mechanisms have been proposed, including reduction of cholesterol, bile acid and neutral sterol secretion into the colon, increased colonic motility, antioxidant properties of coffee ${ }^{(30,31)}$ and reduction of the genotoxicity of several carcinogens by coffee components ${ }^{(32)}$. Animal studies also provide some support ${ }^{(32)}$. The evidence suggests that coffee consumption is possibly related to a decreased risk of colorectal cancer.

\section{CVD}

Intake of coffee has been suspected as a risk factor for CVD. A recent review concluded that no clear association between coffee and the risk of hypertension, myocardial infarction or other CVD could be demonstrated in epidemiological studies ${ }^{(33)}$. Human intervention studies have explored only the short-term effects of coffee consumption on precursors of CVD. Two meta-analyses of RCT on blood pressure ${ }^{(34,35)}$ agreed that coffee consumption can increase blood pressure slightly. Another meta-analysis of fourteen intervention trials showed a significant dose-response relationship between coffee consumption and total or LDL cholesterol levels ${ }^{(36)}$. Although coffee consumption can have acute effects on precursors of CVD, overall, research so far has indicated that moderate coffee intake is probably not associated with increased risk of $\mathrm{CVD}^{(33,37,38)}$.

\section{Other conditions}

The influence of coffee on risk of type 2 diabetes is a relatively new area of research, where five recent reviews have indicated a protective effect ${ }^{(37,39-42)}$. A systematic review of nine cohort and seven cross-sectional studies reported an RR of 0.65 (95\% CI 0.54, 0.78) for the highest $v$. the lowest category of coffee consumption ${ }^{(39)}$. One cohort study $^{(43)}$ and subsequent review ${ }^{(41)}$ indicated that the protective effect may be linked to possible weight loss properties of coffee. While results from mechanistic studies in animals have been inconsistent, possible mechanisms for the effect of coffee components on glucose metabolism have been demonstrated. These include contributing to the in vitro antioxidant capacity of the diet $^{(44)}$, reduction in glucose concentrations ${ }^{(45)}$ and increase in insulin sensitivity ${ }^{(46)}$, inhibition of glucose 
absorption in the intestine ${ }^{(47)}$ and benefits for lipid oxidation $^{(48)}$. Short-term human intervention studies have not shown positive effects on glucose metabo$\operatorname{lism}^{(47,49-52)}$, but these results cannot be extrapolated to long-term effects. Coffee consumption may possibly decrease the risk of type 2 diabetes.

A role for coffee in the prevention of Parkinson's disease is still being debated. A systematic review of thirteen studies ${ }^{(53)}$ reported an overall RR of 0.69 (95\% CI $0.59,0 \cdot 80)$ for coffee $v$. non-coffee drinkers. Of seven additional studies, most demonstrated inverse associations in some groups. However, a biologically plausible mechanism for the role of coffee is currently unavailable $^{(54)}$, so that the evidence for a preventive effect can only be rated as possible.

Epidemiological studies have reported a reduced incidence or mortality for liver cirrhosis with coffee consumption $^{(55)}$. This has been linked to coffee's effect on lowering $\gamma$-glutamyltransferase (GGT) levels, an indicator of cirrhosis risk. However, RCT have shown only slight or no depression of GGT levels by coffee ${ }^{(55)}$. Based on the limited data, it appears possible that coffee consumption is related to a reduced risk of liver cirrhosis.

About twenty-five reviews exist on coffee/caffeine and the risk of unfavourable reproductive outcomes. A review of sixty-eight studies ${ }^{(56)}$ and a systematic review of congenital abnormalities ${ }^{(57)}$ concluded that no convincing evidence has been presented which shows caffeine can increase the risk of any reproductive adversity. Nevertheless, an intake of less than $300 \mathrm{mg}$ caffeine/d for pregnant women was recommended as a precaution ${ }^{(58)}$. Another review of thirty-two studies on caffeine and bone health also concluded 'no evidence that caffeine has any harmful effect on bone status or on the calcium economy in individuals who ingest the currently recommended daily allowances of calcium ${ }^{,(59)}$. Therefore, coffee consumption probably has no relationship with reproductive adversities or bone health.

Finally, coffee has been linked to increased risk of gallstones and rheumatoid arthritis. Data are sparse, but from twelve studies identified on gallstones and six on rheumatoid arthritis, there appears no association between coffee consumption and gallstones or rheumatoid arthritis.

\section{Tea: effects on bealtb}

Of the total tea produced and consumed, $78 \%$ is black, $20 \%$ green and less than $2 \%$ oolong $^{(60)}$. Black tea is consumed primarily in Western countries while green tea is drunk mainly in China, Japan, India and a few countries in North Africa and the Middle East ${ }^{(60)}$. Epidemiological and laboratory evidence is emerging to support early ecological observations that tea drinking may be inversely associated with chronic diseases ${ }^{(61-63)}$. Tea contains various potentially protective compounds such as polyphenols, and much of the effect is attributed to catechins in green tea, especially epigallocatechin-3-gallate (EGCG), and theaflavins and thearubigins in black tea ${ }^{(64)}$.

\section{Cancers}

Epidemiological evidence. Green and black teas have been studied separately for gastrointestinal cancers. A systematic review on gastric cancer suggested a protective effect of green tea on precursors of adenocarcinoma but no clear epidemiological evidence for a protective role in gastric cancer $^{(65)}$. Of twelve additional studies identified, nine showed some decrease in risk with consumption of green tea and almost all experimental studies have demonstrated inhibitory effects on gastrointestinal carcinogenesis ${ }^{(65)}$. From twenty-seven studies, green tea appears to be related to a reduced risk of gastric cancer. A review of gastric cancer and black tea consumption ${ }^{(12)}$ and subsequent studies have mostly reported no association. From nineteen studies, black tea possibly has no relationship with gastric cancer.

Four reviews have examined the relationship between green and/or black tea consumption and risk of colorectal cancer, and concluded there is inconsistent evidence for a protective effect from either tea type $\mathrm{e}^{(28,29,66,67)}$. However, a systematic review of eight studies on green tea reported an OR of $0.82(95 \% \text { CI } 0 \cdot 69,0 \cdot 98)^{(68)}$ and other individual studies on green tea have indicated chemopreventive effects $^{(69-73)}$. From nine studies, green tea consumption is possibly related to a decreased risk of colorectal cancer, while black tea consumption possibly has no relationship with colorectal cancer based on twenty-one studies.

A systematic review of seven studies on green tea and breast cancer incidence reported a pooled RR of 0.89 (95\% CI $0 \cdot 71,1 \cdot 10)$ for consumption of 5 cups or more per $\mathrm{d}^{(74)}$. A meta-analysis of four studies also reported an approximate $20 \%$ risk reduction with high consumption $^{(68)}$. From nine studies, it is possible that intake of green tea is associated with a decreased risk of breast cancer. One meta-analysis ${ }^{(75)}$ and the majority of the seventeen studies concerning black tea and breast cancer reported no association, suggesting that black tea may have no relationship with breast cancer risk. Epidemiological studies on tea and ovarian cancer have generated inconsistent results ${ }^{(76)}$. However, a recent case-control and follow-up study reported a protective effect of green tea on both ovarian cancer risk and survival rates among Chinese women ${ }^{(73,77)}$. Most other studies conducted in populations drinking black tea showed no significant effect. From eleven studies, black tea possibly has no association with ovarian cancer risk whereas green tea consumption possibly decreases risk. Six reviews addressing tea and prostate cancer agreed that epidemiological evidence was not conclusive, but green tea could possibly afford chemopreventive effects ${ }^{(12,62,78-81)}$. Of eleven studies identified, two case-control ${ }^{(82,83)}$ and 
a cohort study ${ }^{(84)}$ have shown a reduced risk. Therefore, tea consumption can possibly reduce the risk of prostate cancer.

There are several potential explanations for the more promising results for green tea than black tea. These include the higher catechin content of green tea and higher level of antioxidant activity ${ }^{(64)}$, consumption of higher volumes of green tea, as well as confounding factors and the small number of published studies.

Other cancers investigated have shown inconsistent results. From fifteen studies on lung cancer, four reviews ${ }^{(12,23,85,86)}$ and a total of thirty-nine studies on urinary tract/bladder cancer, and a pooled analysis of nine case-control studies on thyroid cancer ${ }^{(19)}$, the consumption of tea (black or green) does not appear to lower the risk of lung, urinary tract/bladder or thyroid cancer. Some studies on tea consumption and oesophageal cancer even reported a possible increased risk with the consumption of very hot beverages. From twenty-four studies, tea consumption at normal temperatures probably has no relationship with the risk of oesophageal cancer.

Animal and in vitro evidence. While epidemiological studies have yielded somewhat inconsistent results, quite strong evidence for cancer prevention has emerged from animal and in vitro cell culture studies, especially for green tea ${ }^{(63,87,88)}$. The majority have shown a protective effect at organ sites including the gastrointestinal tract, oral cavity, lung, oesophagus, skin, liver, pancreas, bladder, mammary gland and prostate ${ }^{(87)}$. The antioxidant property of tea polyphenols is the most researched cancer preventive mechanism ${ }^{(89)}$. Antioxidants protect cells against the damaging effects of reactive oxygen species ${ }^{(89)}$. Animal studies have shown that tea catechins increase total plasma antioxidant activity ${ }^{(90,91)}$. Tea catechins also increase the activity of several detoxifying and antioxidant enzymes that can metabolise carcinogens in the body into inactive products ${ }^{(91,92)}$. Moreover, both EGCG and theaflavins in tea can induce apoptosis ${ }^{(93,94)}$ and cell cycle arrest ${ }^{(87)}$. Other in vitro models have shown that tea catechins can inhibit signal transduction pathways mediated by epidermal growth factor and platelet-derived growth factor, favourably affecting angiogenesis $^{(95)}$.

\section{CVD}

Epidemiological evidence. Two reviews on the relationship between tea consumption and CVD concluded that evidence was inconsistent ${ }^{(96,97)}$. A meta-analysis of ten cohort and seven case-control studies examined stroke, myocardial infarction, CHD and tea ${ }^{(98)}$. The results for stroke and CHD were heterogeneous, but the incidence rate of myocardial infarction could decrease by $11 \%$ with an increase in tea consumption of 3 cups/d. Subsequent prospective cohort studies have suggested inverse associations with general $\mathrm{CVD}^{(99)}$, mortality ${ }^{(100)}$, myocardial infarction ${ }^{(101)}$ and important vascular events $^{(102)}$. Evidence has also emerged from a metaanalysis of seven cohort studies of flavonol intake (largely but not exclusively from tea), reporting a reduced risk of CHD mortality with higher consumption ${ }^{(103)}$. Although the majority of studies have been conducted in populations drinking black tea, positive findings are emerging for green tea. For example, the two existing studies on green tea and stroke have both shown protective effects $^{(104,105)}$. In addition, tea consumption has been inversely associated with precursors of CVD including atherosclerosis $^{(101,106)}$ and hypertension ${ }^{(107-109)}$.

Other evidence. Considerable evidence exists from short-term human intervention, animal and in vitro studies that tea consumption could reduce the risk of contributing factors for CVD including hypertension, atherosclerosis and thrombogenesis. Although biological mechanisms for these effects are not completely understood, tea has been shown to affect homocysteine, cholesterol, atherogenesis, inhibit LDL-cholesterol oxidation $^{(110,111)}$ and improve the vascular epithelium ${ }^{(61,96)}$. A review of seventeen human clinical trials reported that tea flavonoids significantly increase the antioxidant capacity of the blood and protect DNA from oxidative damage $^{(112)}$. Furthermore, animal evidence for the positive effects of tea is more consistent than human evidence $^{(113)}$.

\section{Other conditions}

Finally, it has been suggested that tea consumption protects against tooth cavities ${ }^{(114)}$ and kidney stones $^{(115,116)}$, improves immune function ${ }^{(110)}$, and may play a protective role in osteoarthritis ${ }^{(117)}$ and rheumatoid $\operatorname{arthritis}^{(118)}$. However, only preliminary evidence is available so that further research is required.

\section{Discussion}

In summary, although coffee has been suspected of having a variety of adverse effects, research has confirmed that moderate consumption is safe. While potential positive effects of coffee on other conditions are being investigated, the evidence is currently weak. Tea, on the other hand, is a safe beverage that potentially plays a role in the prevention of several cancers and CVD. Evidence from epidemiological studies is not yet conclusive but when animal evidence is considered, especially for green tea, a role for tea in chronic disease prevention looks increasingly promising.

Coffee and tea are both consumed in most countries ${ }^{(2)}$. Worldwide, approximately three cups of tea are drunk for every cup of coffee. Between 1994 and 1996, 76.6\% of tea consumption took place in developing countries with tea 
drinking dominating throughout Asia, the former Soviet Union and Africa. In contrast, $71.5 \%$ of coffee consumption took place in developed countries ${ }^{(2)}$. For example, the apparent per capita consumption of coffee by Australians increased from $0.3 \mathrm{~kg}$ in $1938-39$ to $2.4 \mathrm{~kg}$ in the year ending June 1999. Meanwhile, tea consumption decreased from $3 \cdot 1 \mathrm{~kg}$ to $0.9 \mathrm{~kg}$ over the same period ${ }^{(119)}$.

World trends indicate that beverage consumption is moving away from the potentially healthier choice of tea towards coffee. Current dietary guidelines around the world make little mention of tea and coffee; consequently, the public is not receiving the best available advice on beverage consumption.

In light of the evidence, we are currently able to state that moderate consumption of both coffee and tea is safe. However, the current evidence on protective effects would not be regarded as strong enough to make recommendations for usage of either coffee or tea if the standards of a therapeutic substance were applied. But what if the question is posed in the way that members of the general public ask nutritionists? 'Should I drink coffee or tea?' 'Which is better for me?' If nutritionists are asked to recommend one or the other, we believe the evidence supports recommending tea as a healthy beverage and a better choice than coffee.

In considering whether it is appropriate to make guidelines on tea and coffee, principles underlying nutrition guidelines must be taken into account. All proposed health effects of tea are biologically plausible ${ }^{(4,120)}$. The recommendation is neither inconsistent with previous public health advice ${ }^{(4)}$ nor requires any major deviation from the norm ${ }^{(4,120)}$. Recommending tea consumption is also conservative, with the near absence of risk, and is compatible with one of the traditional principles of medicine, often ascribed to Hippocrates: 'First do no harm'.

The main concern about recommending tea and stating coffee as a safe beverage involves the effects of caffeine. In making guidelines, safe limits must be considered. Based on data reviewed by Nawrot et al. ${ }^{(58)}$, an intake of caffeine at a dose level up to $400 \mathrm{mg} / \mathrm{d}$ (equivalent to $6 \mathrm{mg} / \mathrm{kg}$ body weight per $\mathrm{d}$ in a person weighing $65 \mathrm{~kg}$ ) is not associated with any adverse effect in healthy adults. Using average values for caffeine content presented in Table $6^{(121)}$, this is equivalent to approximately $4-5$ cups of coffee daily or 13 cups of tea (in the absence of other caffeine-containing items). However, such limits should be adjusted for at-risk groups. In the absence of conclusive data, pregnant women or those planning to become pregnant should limit caffeine intake to less than $300 \mathrm{mg} / \mathrm{d}(4.6 \mathrm{mg} / \mathrm{kg}$ body weight per $\mathrm{d}$ in a $65 \mathrm{~kg}$ person) and children to an upper intake of $2.5 \mathrm{mg} / \mathrm{kg}$ body weight per $\mathrm{d}^{(58)}$.

Dietary recommendations are most useful when quantified $^{(12)}$. Although we are able to quantify safe limits for intake of tea and coffee, current evidence is
Table 6 Standard values for caffeine content of tea and coffee ${ }^{(121)}$

\begin{tabular}{lc}
\hline & $\begin{array}{c}\text { Caffeine content } \\
(\mathrm{mg} / 150 \mathrm{ml})\end{array}$ \\
\hline Coffee & \\
$\quad$ Ground roasted (percolated) & 85 \\
Instant & 60 \\
Decaffeinated & 3 \\
Tea & \\
Bagged & 30 \\
Leaf & 30 \\
Instant & 20 \\
\hline
\end{tabular}

insufficient to quantify levels of tea intake necessary for potential health benefits. Epidemiological studies often do not collect data regarding tea preparation and type of tea consumed. Even though some evidence indicates green tea may have greater benefits than black tea, recommendations regarding type of tea cannot be made. The evidence for tea and coffee does not achieve the NHMRC's standards for clinical practice guidelines. The impracticality and high cost of conducting long-term RCT means, realistically, that evidence will not reach this level any time in the near future. Evaluation of evidence for therapeutic and preventive measures should follow separate guidelines ${ }^{(9)}$. People worldwide will continue to drink tea and coffee, so that professional nutritionists must offer advice on the best available evidence rather than waiting until higher levels of evidence become available.

\section{Conclusion}

Tea and coffee are consumed by millions of people around the world every day. However, little dietary advice exists on the consumption of these beverages. Current evidence on the health effects of tea and coffee does not meet the NHMRC's level for clinical practice guidelines $^{(8)}$. Nevertheless, evidence indicates that coffee is a safe beverage, while tea consumption is possibly protective against several cancers and CVD. Worldwide, consumption of tea is decreasing whereas coffee is increasing. In light of the evidence, nutritionists should advocate tea as part of a healthy diet and as a superior choice to coffee despite the fact that levels of intake cannot currently be recommended. The answer to our title question: we would like tea please.

\section{Acknowledgements}

There are no conflicts of interest to be declared by the authors. The funding for the project was provided by Curtin University, Perth, Western Australia.

Authorship responsibilities: All authors contributed significantly to the project. C.W.B. initiated the project, 
provided references and participated in rating the studies and editing of the manuscript. A.H.L. provided references and participated in rating the studies and editing of the manuscript. M.L.F. undertook literature searches and wrote the first draft of the manuscript.

\section{References}

1. Caraher M \& Coveney J (2004) Public health nutrition and food policy. Public Health Nutr 7, 591-598.

2. Grigg D (2002) The worlds of tea and coffee: patterns of consumption. GeoJournal 57, 283-294.

3. Stewart BW \& Kleihues P (2003) World Cancer Report. Lyon: International Agency for Research on Cancer.

4. Binns CW \& Lee MK (2001) Translating nutrition science into dietary guidelines: evidence and benchmarking. J Korean Diet Assoc 17, 202-207.

5. Trichopoulos D, Lagiou P \& Trichopoulou A (2000) Evidence-based nutrition. Asia Pac J Clin Nutr 9, S4-S9.

6. Wahlqvist ML, Kouris-Blazos A \& Wattanapenpaiboon N (1999) The significance of eating patterns: an elderly Greek case study. Appetite 32, 23-32.

7. Keys A (1980) Seven Countries: A Multivariate Analysis of Death and Coronary Heart Disease. Cambridge, MA: Harvard University Press.

8. National Health and Medical Research Council (1999) A Guide to the Development, Implementation and Evaluation of Clinical Practice Guidelines. Canberra: NHMRC.

9. Kroke A, Boeing H, Rossnagel K \& Willich SN (2004) History of the concept of 'levels of evidence' and their current status in relation to primary prevention through lifestyle interventions. Public Health Nutr 7, 279-284.

10. Margetts B, Warm D, Yngve A \& Sjostrom M (2001) Developing an evidence-based approach to public health nutrition: translating evidence into policy. Public Health Nutr 4, 1393-1397.

11. Wanless D (2004) Securing Good Health for the Whole Population: Final Report. London: Her Majesty's Stationery Office.

12. World Cancer Research Fund/American Institute for Cancer Research (1997) Food Nutrition and the Prevention of Cancer: A Global Perspective. Washington, DC: AICR.

13. International Agency for Research on Cancer (1991) Coffee, Tea, Mate, Methylxanthines and Methylglyoxa. Monographs on the Evaluation of the Carcinogenic Risk of Chemicals to Humans no. 51. Lyon: IARC.

14. La Vecchia C, Liati P, Decarli A, Negri E \& Franceschi S (1987) Coffee consumption and risk of pancreatic cancer. Int J Cancer 40, 309-313.

15. Gordis L (1990) Consumption of methylxanthinecontaining beverages and risk of pancreatic cancer. Cancer Lett 52, 1-12.

16. Qiu D, Kurosawa M, Lin Y, Inaba Y, Matsuba T, Kikuchi S, Yagyu K, Motohashi Y, Tamakoshi A. JACC Study Group. Overview of the epidemiology of pancreatic cancer focusing on the JACC Study. J Epidemiol 15, Suppl. 2, S157-S167.

17. Larsson SC \& Wolk A (2005) Coffee consumption is not associated with ovarian cancer incidence. Cancer Epidemiol Biomarkers Prev 14, 2273-2274.

18. Dhote R, Pellicer-Coeuret M, Thiounn N, Debre B \& VidalTrecan G (2000) Risk factors for adult renal cell carcinoma: a systematic review and implications for prevention. BJU Int 86, 20-27.

19. Mack WJ, Preston-Martin S, Dal Maso L, Galanti R, Xiang M \& Franceschi S (2003) A pooled analysis of case-control studies of thyroid cancer: cigarette smoking and consumption of alcohol, coffee and tea. Cancer Causes Control 14, 773-785.

20. Dagnelie PC, Schuurman AG, Goldbohm RA \& van den Brandt PA (2004) Diet, anthropometric measures and prostate cancer risk: a review of prospective cohort and intervention studies. BJU Int 93, 1139-1150.

21. Viscoli CM, Lachs MS \& Horwitz RI (1993) Bladder cancer and coffee drinking: a summary of case-control research. Lancet 341, 1432-1437.

22. Sala M, Cordier S, Chang-Claude J et al. (2000) Coffee consumption and bladder cancer in non-smokers: a pooled analysis of case-control studies in European countries. Cancer Causes Control 11, 925-931.

23. Zeegers MPA, Tan FES, Goldbohm RA \& van den Brandt PA (2002) Are coffee and tea consumption associated with urinary tract cancer risk? A systematic review and meta-analysis. Int J Epidemiol 30, 353-362.

24. Pelucchi C, Bosetti C, Negri E, Malvezzi M \& La Vecchia C (2006) Mechanisms of disease: the epidemiology of bladder cancer. Nat Clin Pract Urol 3, 327-340.

25. Villanueva CM, Cantor KP, King WD, Jaakkola JJ, Cordier S, Lynch CF, Porru S \& Kogevinas M (2006) Total and specific fluid consumption as determinants of bladder cancer risk. Int J Cancer 118, 2040-2047.

26. Zeegers MPA, Kellen E, Buntinx F \& van den Brandt PA (2004) The association between smoking, beverage consumption, diet and bladder cancer: a systematic literature review. World J Urol 21, 392-401.

27. Giovannucci E (1998) Meta-analysis of coffee consumption and risk of colorectal cancer. Am J Epidemiol 147, 1043-1052.

28. Tavani A \& La Vecchia C (2004) Coffee, decaffeinated coffee, tea and cancer of the colon and rectum: a review of epidemiological studies, 1990-2003. Cancer Causes Control 15, 743-757.

29. Marques-Vidal P, Ravasco P \& Ermelinda Camilo M (2006) Foodstuffs and colorectal cancer risk: a review. Clin Nutr 25, 14-36.

30. Daglia M, Papetti A, Gregotti C, Berte F \& Gazzani G (2002) In vitro antioxidant and ex vivo protective activities of green and roasted coffee. J Agric Food Chem 48, $1449-1454$

31. Anese M \& Nicoli MC (2003) Antioxidant properties of ready-to-drink coffee brews. J Agric Food Chem 51, 942-946.

32. Cavin C, Holzhaeuser D, Scharf G, Constable A, Huber WW \& Schilter B (2002) Cafestol and kahweol, two coffee specific diterpenes with anticarcinogenic activity. Food Chem Toxicol 40, 1155-1163.

33. Sudano I, Binggeli C, Spieker L, Luscher TF, Ruschitzka F, Noll G \& Corti R (2005) Cardiovascular effects of coffee: is it a risk factor? Prog Cardiovasc Nurs 20, 65-69.

34. Jee SH, He J, Whelton PK, Suh I \& Klag MJ (1999) The effect of chronic coffee drinking on blood pressure: a meta-analysis of controlled clinical trials. Hypertension 33, $647-652$.

35. Noordzij M, Uiterwaal CS, Arends LR, Kok FJ, Grobbee DE \& Geleijnse JM (2005) Blood pressure response to chronic intake of coffee and caffeine: a meta-analysis of randomized controlled trials. J Hypertens 23, 921-928.

36. Jee SH, He J, Appel LJ, Whelton PK, Suh I \& Klag MJ (2001) Coffee consumption and serum lipids: a metaanalysis of randomized controlled clinical trials. $\mathrm{Am} \mathrm{J}$ Epidemiol 153, 353-362.

37. Ranheim T \& Halvorsen B (2005) Coffee consumption and human health - beneficial or detrimental? - mechanisms for effects of coffee consumption on different risk factors for cardiovascular disease and type 2 diabetes mellitus. Mol Nutr Food Res 49, 274-284. 
38. Cornelis MC \& El-Sohemy A (2007) Coffee, caffeine, and coronary heart disease. Curr Opin Lipidol 18, 13-19.

39. van Dam RM \& Hu FB (2005) Coffee consumption and risk of type 2 diabetes: a systematic review. JAMA 294, 97-104.

40. Murakami K, Okubo H \& Sasaki S (2005) Effect of dietary factors on incidence of type 2 diabetes: a systematic review of cohort studies. J Nutr Sci Vitaminol 51, 292-310.

41. Greenberg JA, Boozer CN \& Geliebter A (2002) Coffee, diabetes, and weight control. Am J Clin Nutr 84, 682-693.

42. van Dam RM (2006) Coffee and type 2 diabetes: from beans to $\beta$-cells. Nutr Metab Cardiovasc Dis 16, 69-77.

43. Greenberg JA, Axen KV, Schnoll R \& Boozer CN (2005) Coffee, tea and diabetes: the role of weight loss and caffeine. Int J Obes Relat Metab Disord 29, 1121-1129.

44. Svilaas A, Sakhi AK, Andersen LF, Svilaas T, Strom EC, Jacobs DR Jr, Ose L \& Blomhoff R (2004) Intakes of antioxidants in coffee, wine, and vegetables are correlated with plasma carotenoids in humans. J Nutr 134, 562-567.

45. Rodriguez de Sotillo DV \& Hadley M (2002) Chlorogenic acid modifies plasma and liver concentrations of cholesterol, triacylglycerol, and minerals in (fa/fa) Zucker rats. J Nutr Biochem 13, 717-726.

46. Shearer J, Farah A, de Paulis T, Bracy DP, Pencek RR, Graham TE \& Wasserman DH (2003) Quinides of roasted coffee enhance insulin action in conscious rats. $J$ Nutr 133, 3529-3532.

47. Johnston KL, Clifford MN \& Morgan LM (2003) Coffee acutely modifies gastrointestinal hormone secretion and glucose tolerance in humans: glycemic effects of chlorogenic acid and caffeine. Am J Clin Nutr 78, 728-733.

48. Yoshioka K, Kogure A, Yoshida T \& Yoshikawa T (2003) Coffee consumption and risk of type 2 diabetes mellitus. Lancet 361, 703 .

49. van Dam RM, Pasman WJ \& Verhoef P (2004) Effects of coffee consumption on fasting blood glucose and insulin concentrations: randomized controlled trials in healthy volunteers. Diabetes Care 27, 2990-2992.

50. Keijzers GB, De Galan BE, Tack CJ \& Smits P (2002) Caffeine can decrease insulin sensitivity in humans. Diabetes Care 25, 364-369.

51. Lane JD, Barkauskas CE, Surwit RS \& Feinglos MN (2004) Caffeine impairs glucose metabolism in type 2 diabetes. Diabetes Care 27, 2047-2048.

52. Battram DS, Arthur R, Weekes A \& Graham TE (2006) The glucose intolerance induced by caffeinated coffee ingestion is less pronounced than that due to alkaloid caffeine in men. J Nutr 136, 1276-1280.

53. Hernan MA, Takkouche B, Caamano-Isorna F \& GestalOtero JJ (2002) A meta-analysis of coffee drinking, cigarette smoking, and the risk of Parkinson's disease. Ann Neurol 52, 276-284.

54. Joghataie MT, Roghani M, Negahdar F \& Hashemi L (2004) Protective effect of caffeine against neurodegeneration in a model of Parkinson's disease in rat: behavioural and histochemical evidence. Parkinsonism Relat Disord 10, $465-468$.

55. La Vecchia C (2005) Coffee, liver enzymes, cirrhosis and liver cancer. J Hepatol 42, 444-446.

56. Leviton A \& Cowan L (2002) A review of the literature relating caffeine consumption by women to their risk of reproductive hazards. Food Chem Toxicol 40, 1271-1310.

57. Browne ML (2006) Maternal exposure to caffeine and risk of congenital anomalies: a systematic review. Epidemiology 17, 324-331.

58. Nawrot P, Jordan S, Eastwood J, Rotstein J, Hugenholtz A \& Feeley M (2003) Effects of caffeine on human health. Food Addit Contam 20, 1-30.
59. Heaney RP (2002) Effects of caffeine on bone and the calcium economy. Food Chem Toxicol 40, 1263-1270.

60. Mukhtar H \& Ahmad N (2000) Tea polyphenols: prevention of cancer and optimizing health. Am J Clin Nutr $\mathbf{7 1}$, 1698S-1702s.

61. Cheng TO (2006) All teas are not created equal: the Chinese green tea and cardiovascular health. Int J Cardiol 108, 301-308.

62. Lee AH, Fraser ML, Meng X \& Binns CW (2006) Protective effects of green tea against prostate cancer. Expert Rev Anticancer Ther 6, 507-513.

63. Cabrera C, Artacho R \& Gimenez R (2006) Beneficial effects of green tea - a review. J Am Coll Nutr 25, 79-99.

64. Graham HN (1992) Green tea composition, consumption, and polyphenol chemistry. Prev Med 21, 334-350.

65. Borrelli F, Capasso R, Russo A \& Ernst E (2004) Systematic review: green tea and gastrointestinal cancer risk. Aliment Pharmacol Ther 19, 497-510.

66. Arab L \& Il'yasova D (2003) The epidemiology of tea consumption and colorectal cancer incidence. J Nutr $\mathbf{1 3 3}$, 3310S-3318S.

67. Suzuki Y, Tsubono Y, Nakaya N, Koizumi Y, Shibuya D \& Tsuji I (2005) Green tea and the risk of colorectal cancer: pooled analysis of two prospective studies in Japan. J Epidemiol 15, 118-124.

68. Sun CL, Yuan JM, Koh WP \& Yu MC (2006) Green tea, black tea and colorectal cancer risk: a meta-analysis of epidemiologic studies. Carcinogenesis 27, 1301-1309.

69. Nakachi K, Matsuyama S, Miyake S, Suganuma M \& Imai K (2000) Preventive effects of drinking green tea on cancer and cardiovascular disease: epidemiological evidence for multiple targeting prevention. Biofactors 13, 49-54.

70. Inoue $M$, Tajima $K$, Mizutani $M$, Iwata $H$, Iwase $T$, Miura S, Hirose K, Hamajima N \& Tominaga S (2001) Regular consumption of green tea and the risk of breast cancer recurrence: follow-up study from the Hospital-Based Epidemiologic Research Program at Aichi Cancer Center (HERPACC), Japan. Cancer Lett 167, 175-182.

71. Ji BT, Chow WH, Hsing AW, McLaughlin JK, Dai Q, Gao YT, Blot WJ \& Fraumeni JF Jr (1997) Green tea consumption and the risk of pancreatic and colorectal cancers. Int J Cancer 70, 255-258.

72. Kato I, Tominaga S, Matsuura A, Yoshii Y, Shirai M \& Kobayashi S (1990) A comparative case-control study of colorectal cancer and adenoma. Jpn J Cancer Res $\mathbf{8 1}$, 1101-1108.

73. Zhang M, Binns CW \& Lee AH (2002) Tea consumption and ovarian cancer risk: a case control study in China. Cancer Epidemiol Biomarkers Prev 11, 713-718.

74. Seely D, Mills EJ, Wu P, Verma S \& Guyatt GH (2005) The effects of green tea consumption on incidence of breast cancer: a systematic review and meta-analysis. Integr Cancer Ther 4, 144-155.

75. Sun CL, Yuan JM, Koh WP \& Yu MC (2006) Green tea, black tea and breast cancer risk: a meta-analysis of epidemiological studies. Carcinogenesis 27, $1310-1315$.

76. Lee AH, Fraser ML \& Binns CW (2005) Possible role for green tea in ovarian cancer prevention. Future Oncol 1, $771-777$.

77. Zhang M, Lee AH, Binns CW \& Xie X (2004) Green tea consumption enhances survival of epithelial ovarian cancer. Int J Cancer 112, 465-469.

78. Saleem M, Adhami VM, Siddiqui IA \& Mukhtar H (2003) Tea beverage in chemoprevention of prostate cancer: a mini-review. Nutr Cancer 47, 13-23.

79. Adhami VM \& Mukhtar H (2006) Polyphenols from green tea and pomegranate for prevention of prostate cancer. Free Radic Res 40, 1095-1104. 
80. Neill MG \& Fleshner NE (2006) An update on chemoprevention strategies in prostate cancer for 2006. Curr Opin Urol 16, 132-137.

81. Siddiqui IA, Adhami VM, Saleem M \& Mukhtar H (2006) Beneficial effects of tea and its polyphenols against prostate cancer. Mol Nutr Food Res 50, 130-143.

82. Jain MG, Hislop GT, Howe GR, Burch JD \& Ghadirian P (1998) Alcohol and other beverage use and prostate cancer risk among Canadian men. Int J Cancer 78, 707-711.

83. Jian L, Xie LP, Lee AH \& Binns CW (2004) Protective effect of green tea against prostate cancer: a case control study in Southeast China. Int J Cancer 108, 130-135.

84. Heilbrun LK, Nomura A \& Stemmermann GN (1986) Black tea consumption and cancer risk: a prospective study. $\mathrm{Br} J$ Cancer 54, 677-683.

85. Zeegers MP, Kellen E, Buntinx F \& van den Brandt PA (2004) The association between smoking, beverage consumption, diet and bladder cancer: a systematic literature review. World J Urol 21, 392-401.

86. Leppert JT, Shvarts O, Kawaoka K, Lieberman R, Belldegrun AS \& Pantuck AJ (2006) Prevention of bladder cancer: a review. Eur Urol 49, 226-234.

87. Chung FL, Schwartz J, Herzog CR \& Yang YM (2003) Tea and cancer prevention: studies in animals and humans. J Nutr 133, 3268S-3274S.

88. Yang CS, Lambert JD, Hou Z, Ju J, Lu G \& Hao X (2006) Molecular targets for the cancer preventive activity of tea polyphenols. Mol Carcinog 45, 431-435.

89. Crespy V \& Williamson G (2004) A review of the health effects of green tea catechins in in vivo animal models. J Nutr 134, 3431S-3440S.

90. Yokozawa T, Nakagawa T \& Kitani K (2002) Antioxidative activity of green tea polyphenol in cholesterol-fed rats. J Agric Food Chem 50, 3549-3552.

91. Skrzydlewska E, Ostrowska J, Farbiszewski R \& Michalak K (2002) Protective effect of green tea against lipid peroxidation in the rat liver, blood serum and the brain. Phytomedicine 9, 232-238.

92. Donovan JL, Crespy V, Manach C, Morand C, Besson C, Scalbert A \& Rémésy C (2001) Catechin is metabolized by both the small intestine and liver of rats. $J$ Nutr 131, 1753-1757.

93. Lu YP, Lou YR, Li XH, Xie JG, Brash D, Huang MT \& Conney AH (2000) Stimulatory effect of oral administration of green tea or caffeine on ultraviolet light-induced increases in epidermal wild-type p53, p21(WAF1/CIP1), and apoptotic sunburn cells in SKH-1 mice. Cancer Res 60, 4785-4791.

94. Gupta S, Hastak K, Ahmad N, Lewin JS \& Mukhtar H (2001) Inhibition of prostate carcinogenesis in TRAMP mice by oral infusion of green tea polyphenols. Proc Natl Acad Sci USA 98, 10350-10355.

95. Wiseman S, Mulder T \& Rietveld A (2001) Tea flavonoids: bioavailability in vivo and effects on cell signalling pathways in vitro. Antioxid Redox Signal 3, 1009-1021.

96. Vita JA (2003) Tea consumption and cardiovascular disease: effects on endothelial function. $J$ Nutr 133, 3293S-3297S

97. Kris-Etherton PM, Hecker KD, Bonanome A, Coval SM, Binkoski AE, Hilpert KF, Griel AE \& Etherton TD (2002) Bioactive compounds in foods: their role in the prevention of cardiovascular disease and cancer. Am J Med $\mathbf{1 1 3}$, 71S-88S

98. Peters U, Poole C \& Arab L (2001) Does tea affect cardiovascular disease? A meta-analysis. Am J Epidemiol 154, 495-503.

99. Kuriyama S, Shimazu T, Ohmori K, Kikuchi N, Nakaya N, Nishino Y, Tsubono Y \& Tsuji I (2006) Green tea consumption and mortality due to cardiovascular disease, cancer, and all causes in Japan: the Ohsaki study. JAMA 296, 1255-1265.
100. Shimazu T, Kuriyama S, Hozawa A, Ohmori K, Sato Y, Nakaya N, Nishino Y, Tsubono Y \& Tsuji I (2007) Dietary patterns and cardiovascular disease mortality in Japan: a prospective cohort study. Int J Epidemiol 36, 610-611.

101. Geleijnse JM, Launer LJ, Van der Kuip DA, Hofman A \& Witteman JC (2002) Inverse association of tea and flavonoid intakes with incident myocardial infarction: the Rotterdam study. Am J Clin Nutr 75, 880-886.

102. Sesso HD, Gaziano JM, Liu S \& Buring JE (2003) Flavonoid intake and the risk of cardiovascular disease in women. Am J Clin Nutr 77, 1400-1408.

103. Huxley RR \& Neil HAW (2003) The relation between dietary flavonol intake and coronary heart disease mortality: a meta-analysis of prospective cohort studies. Eur J Clin Nutr 57, 904-908.

104. Sato Y, Nakatsuka H, Watanabe $\mathrm{T}$ et al. Possible contribution of green tea drinking habits to the prevention of stroke. Tohoku J Exp Med 157, 337-343.

105. Chen Z, Li Y, Zhao LC, Zhou BF, Yang J, Wang ZW, Guo M \& Wu YF (2004) A study on the association between tea consumption and stroke. Zhonghua Liu Xing Bing Xue Za Zbi 25, 666-670.

106. Sasazuki S, Kodama H, Yoshimasu K et al. (2000) Relation between green tea consumption and the severity of coronary atherosclerosis among Japanese men and women. Ann Epidemiol 10, 401-408.

107. Hodgson JM, Devine A, Puddey IB, Chan SY, Beilin LJ \& Prince RL (2003) Tea intake is inversely related to blood pressure in older women. Asia Pac J Clin Nutr 12, S18.

108. Yang YC, Lu FH, Wu JS, Wu CH \& Chang CJ (2004) The protective effect of habitual tea consumption on hypertension. Arch Intern Med 164, 1534-1540.

109. Hodgson JM (2006) Effects of tea and tea flavonoids on endothelial function and blood pressure: a brief review. Clin Exp Pharmacol Physiol 33, 838-841.

110. Trevisanato SI \& Kim YI (2000) Tea and health. Nutr Rev 58, $1-10$.

111. Stangl V, Lorenz M \& Stangl K (2006) The role of tea and tea flavonoids in cardiovascular health. Mol Nutr Food Res 50, 218-228.

112. Rietveld A \& Wiseman S (2003) Antioxidant effects of tea: evidence from human clinical trials. J Nutr 133, 3285S-3292S.

113. Zhao W \& Chen J (2001) Candidate foods in the AsiaPacific region for cardiovascular protection: oriental tea. Asia Pac J Clin Nutr 10, 138-142.

114. Wu CD \& Wei GX (2002) Tea as a functional food for oral health. Nutrition 18, 443-444.

115. Jeong BC, Kim BS, Kim JI \& Kim HH (2006) Effects of green tea on urinary stone formation: an in vivo and in vitro study. J Endourol 20, 356-361.

116. Itoh Y, Yasui T, Okada A, Tozawa K, Hayashi Y \& Kohri K (2005) Preventive effects of green tea on renal stone formation and the role of oxidative stress in nephrolithiasis. J Urol 173, 271-275.

117. Fajardo M \& Di Cesare PE (2005) Disease-modifying therapies for osteoarthritis: current status. Drugs Aging 22, 141-161.

118. Mikuls TR, Cerhan JR, Criswell LA, Merlino L, Mudano AS, Burma M, Folsom AR \& Saag KG (2002) Coffee, tea, and caffeine consumption and risk of rheumatoid arthritis: results from the Iowa Women's Health Study. Arthritis Rheum 46, 83-91.

119. Australian Bureau of Statistics (2000) Apparent Consumption of Foodstuffs: Australia. Catalogue no. 4306.0. Canberra: ABS.

120. McKay DL \& Blumberg JB (2002) The role of tea in human health: an update. J Am Coll Nutr 21, 1-13.

121. Barone JJ \& Roberts HR (1996) Caffeine consumption. Food Chem Toxicol 34, 119-129. 